\title{
Perfil e percepções de futuras educadoras do campo a partir do ingresso em Universidade Pública
}

\author{
Laura Jane Gisloti ${ }^{1}$ \\ ORCID: 0000-0002-3954-0245 \\ Dalva Melo dos Santos ${ }^{1}$ \\ ORCID: 0000-0003-1601-8400 \\ Cíntia Melo dos Santos ${ }^{1}$ \\ ORCID: 0000-0003-2121-3120 \\ Sandra Procópio da Silva ${ }^{1}$ \\ ORCID: 0000-0002-4294-7679
}

\section{Resumo}

0 presente estudo teve por objetivo reunir antecedentes, motivações e percepções das futuras professoras formadas no Curso de Licenciatura em Educação do Campo (LEDUC) da Universidade Federal da Grande Dourados (UFGD), a partir do ingresso no curso. A partir de instrumentos de pesquisa misto de caráter quantitativo e qualitativo (questionário estruturado com questões abertas e fechadas e entrevista semiestruturada) e da análise de conteúdo dos discursos obtidos, discutimos e refletimos a respeito de duas dimensões fundamentais: o perfil das mulheres estudantes que buscam a Educação do Campo e a percepção delas a respeito do impacto em suas vidas após o ingresso na universidade. 0 perfil das mulheres é de idade inferior a 28 anos, moradoras do campo, solteiras e sem filhos. Cursaram o ensino médio em escolas do campo e encontraram na LEDUC a possibilidade de ingresso no ensino superior devido a vários fatores, dentre eles, o método da Pedagogia da Alternância, no qual se alterna o processo de ensino-aprendizagem entre o tempo-universidade e o tempocomunidade, possibilitando, assim, que estudem de acordo com suas condições objetivas. Tais mulheres ainda não estão inseridas profissionalmente nas escolas do campo, se identificam como estudantes, enfrentaram desafios relacionados a questões de gênero e acreditam que o curso propiciou uma mudança na relação com a vida no campo, profissional (35\%), doméstica (31\%) e socialmente (30\%). Refletimos que a inserção dessas mulheres no curso favorece a tomada de outros papéis sociais fazendo com que se reconheçam como sujeitas atuantes na construção da Educação do Campo, na universidade e em suas comunidades, a partir da valorização de seu modo de vida e dos saberes associados, além de contribuir com a transformação da cultura patriarcal tão presente na cultura do campesinato.

1- Universidade Federal da Grande Dourados, Dourados MS, Brasil. Contatos: lauragisloti@gmail.com; dalvamelos@hotmail.com; cintiamelos@ hotmail.com; sandraprocopio@ufgd.edu.br

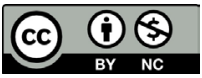




\title{
Palavras-chave
}

Camponesas - Estudantes - Mulheres do campo - Perfil.

\section{Profile and perceptions of future rural educators upon entering Public University}

\begin{abstract}
The objective of this study is to gather antecedents, motivations and perceptions of teachers who will study and attain their bachelor's degree in Rural Education (LEDUC) at the Federal University of Grande Dourados (UFGD). From research instruments of mixed quantitative and qualitative character (a questionnaire structured with open and closed questions and a semi-structured interview) and the analysis of the content of two speeches obtained, we discuss and analyze them in the context of two fundamental dimensions: the profile of women students who are looking to take Rural Education and their perception when it comes to its impact on their lives after they had been admitted to the university. The women's profile of women shows they are under 28 years old, rural residents, single and childless. They attended high school in rural schools and found in LEDUC the possibility of entering higher education due to several factors, including the Alternation Pedagogy method, in which the teaching-learning process alternates between time at the university and time at the community. This allows them to study according to their objective conditions. These women are still not professionally inserted in rural schools, they identify themselves as students, they have faced gender-related challenges and they believe the course has changed their relationships with the non-country life, professional life (35\%), domestic life (31\%) and social life (30\%). We reaffirm that the entry of women in this course favors them to take other roles in society, making them recognize themselves as agents that help the construction of Rural Education at the university and in their communities because of their appreciation of their way of life and the associated knowledge they possess, in addition to contributing to the transformation of the patriarchal culture that is present in peasant culture.
\end{abstract}

\section{Keywords}

Peasant women - Students - Women from rural areas - Profile. 


\section{Introdução}

A Educação do Campo surgiu no âmago dos movimentos sociais, sendo o principal deles o Movimento dos Trabalhadores Sem Terra (MST) que, desde os anos 1980, tem pressionado o Estado para que ofereça educação específica e de qualidade para as populações rurais, isto é, uma educação que faça sentido e dialogue com modos de vida camponês e cujo princípio seja norteado pela luta pela terra e pelo modelo de agricultura familiar em oposição ao agronegócio e à ideologia capitalista. Assim, a Educação do Campo tem como base a democratização do acesso ao conhecimento, reconhecendo sua importância estratégica na melhoria de agentes capazes de construir alternativas populares para a sociedade (CALDART, 2008; ARROYO, 2012). Assim, está intimamente ligada aos movimentos sociais do campo e a luta e resistência para acesso e produção de conhecimento, educação e cultura, desenvolvendo um movimento contra hegemônico às ideologias dominantes que marginalizam as populações campesinas (MOLINA; FREITAS, 2011).

Nesse contexto, o curso de Licenciatura em Educação do Campo (LEDUC) foi criado na Universidade Federal da Grande Dourados (UFGD) em 2013, a fim de formar professoras e professores para atuarem nos processos pedagógicos e na gestão das escolas básicas do meio rural, em sintonia com os modos de vida, as identidades, culturas e lutas do campesinato. 0 curso funciona por meio da Pedagogia da Alternância que se fundamenta em uma pedagogia em movimento, já que há alternância entre tempouniversidade (as/os acadêmicas/os estão na faculdade com aulas em período integral) e o tempo-comunidade (as/os professores se deslocam até os assentamentos/sítios/chácaras, aldeias e comunidades tradicionais para ministrar aulas). A presente pedagogia visa a intervir na realidade da comunidade, unindo os conhecimentos teorizados com a prática, visando assim ao enriquecimento da prática escolar e, principalmente, possibilitando a formação acadêmica sem que as/os estudantes deixem a vida do campo para terem acesso às instituições de ensino (CALDART, 2012; MOLINA, 2015).

Portanto, as Licenciaturas em Educação do Campo visam a formar educadoras e educadores capazes de compreender as contradições sociais, culturais e econômicas vivenciados em suas comunidades, para assim desenvolver práticas educativas que capacitam essas pessoas na superação dessas contradições. Dessa forma, esses cursos pretendem formar educadoras/es comprometidas/os com o projeto de desenvolvimento rural, que valorizem suas condições e formas de vida, que promovam a agricultura familiar camponesa e causem tensão ao modelo de agronegócio hegemônico para o campo (FALEIR0; FARIAS, 2017). Sendo assim, a expansão da oferta de cursos de Licenciatura em Educação do Campo no sistema público de ensino superior no Brasil não pode ser compreendida separadamente do intenso conflito que busca a manutenção do modelo de desenvolvimento hegemônico para o campo (ARROYO, 2009; MOLINA, 2015).

Nesse sentido, a concepção de Educação do Campo presente neste artigo é a de que se trata de uma construção pautada no coletivo, que tem início com a crítica das práticas desenvolvidas nas escolas dos assentamentos da reforma agrária e é ampliada para o âmbito das políticas públicas, em especial pelas lutas pelo acesso à educação básica e superior, contra o fechamento de escolas, pela formação específica das e dos 
professores e infraestrutura adequada nas escolas. Trata-se de uma construção que surge no interior do movimento social, que questiona a lógica educacional convencional, os direitos sociais, a cultura do fazer política educacional e o histórico padrão segregador e insular de conhecimentos (ARROYO, 2007).

Para além desses aspectos, a Educação do Campo propõe uma reflexão a respeito das identidades feminina e masculina, trazendo para a agenda temática das discussões a problemática das relações de poder que perpassam o gênero. É possível observarmos uma nova construção na dinâmica das relações de gêneros nos assentamentos da reforma agrária, de forma que se tem notado um incremento e um aprofundamento na participação das mulheres nos processos de formação política e na escolarização formal nos diferentes tipos de desdobramentos, principalmente no que diz respeito ao protagonismo delas nos espaços de convivência em seus assentamentos de origem (PEREIRA, 2016).

Consequentemente, é notável a importância das mulheres camponesas na construção de um novo modelo de desenvolvimento sustentável no meio rural, baseado em formas familiares e coletivas de produção. As pautas referentes à: alimentação saudável (com diversidade de alimentos livres de contaminação); valorização do uso de plantas medicinais e de outras práticas de medicina natural e ao combate ao uso dos agrotóxicos são aspectos importantes acerca da sustentabilidade desse modelo que vem sendo pautado pelos movimentos de mulheres, assim como a mudança no relacionamento entre as pessoas e entre essas pessoas e o meio no qual vivem e trabalham (MOLINA; FREITAS, 2011; TARDIN, 2012).

Dessa forma, o presente estudo foca-se nas mulheres estudantes da LEDUC da Universidade Federal da Grande Dourados, a fim de identificar o seu perfil, além de refletir a respeito de seus aspectos escolares e profissionais e ainda identificar a percepção dessas estudantes em relação ao impacto em suas vidas após o ingresso no curso.

\section{Metodologia}

Partimos de uma abordagem mista, de forma a estabelecer conexões entre as abordagens qualitativa e quantitativa e, considerando as três estratégias de investigação subjacentes aos métodos mistos indicadas por Creswell (2010), optamos pelo procedimento sequencial (em que a recolha de dados foi realizada sequencialmente), de forma a possibilitar que a análise da investigação fosse abrangente, considerando a sua multidimensionalidade. 0 pressuposto central que justifica a abordagem do método misto é o de que a interação entre os métodos fornece melhores possibilidades analíticas, já que é possível correlacionar os métodos predeterminados das pesquisas quantitativas com os das qualitativas, por meio de formas múltiplas de dados que contemplem inúmeras possibilidades, incluindo análises estatísticas e análises textuais. Da mesma forma, a produção e a interpretação dos resultados foram realizadas mediante a incorporação e a integração dos elementos obtidos a partir dos diferentes tipos de dados recolhidos (de natureza qualitativa e quantitativa) (CRESWELL; CLARK, 2011).

Nesse sentido, avaliamos que o questionário estruturado com questões abertas e fechadas seria um instrumento viável, pois possibilita identificar o perfil das mulheres 
por meio de questões diretas garantindo o anonimato das envolvidas e possibilitando que tenham tempo para refletir acerca das questões propostas (RIBEIR0, 2008). No entanto, no decorrer da pesquisa sentimos a necessidade de recorrer a entrevistas semiestruturadas, no sentido de aprofundar questões abordadas no questionário, já que a grande vantagem da entrevista sobre outras técnicas é a de que ela permite a captação imediata, sensível e corrente da informação desejada (LUDKE; ANDRÉ, 2013).

Em relação ao questionário, todas as estudantes foram esclarecidas quanto aos objetivos da pesquisa e assim a amostra foi definida como amostra completa, já que todas as estudantes presentes no curso no momento da pesquisa (de março a outubro de 2017), ou seja, todas mulheres matriculadas no primeiro semestre de 2017 da LEDUC (habilitação em Ciências da Natureza), ingressantes nos anos de 2013, 2014 e 2017 (primeira, segunda e terceira turma, respectivamente) $(n=52)$, concordaram em participar da pesquisa de forma livre e esclarecida.

0 questionário consistiu em abordar: (1) Aspectos sociais (idade, estado civil, número de filhos, local e situação da moradia), que visa a verificar o perfil dessas estudantes; (2) Aspectos escolares e de trabalho (onde cursou o ensino médio, se teve outra oportunidade de ingressar no ensino superior, profissão), a fim de traçar o histórico escolar e profissional; e (3) Percepção sobre o impacto do ingresso na Educação do Campo na vida das estudantes.

Já as entrevistas semiestruturadas foram realizadas com nove estudantes da primeira turma (2013) que, de maneira livre e esclarecida, concordaram em gravar em vídeo suas reflexões acerca das dificuldades encontradas e avanços percebidos durante a trajetória acadêmica.

No tocante aos procedimentos do tratamento dos dados e das formas de análise, recorremos ao uso da distribuição de frequência e percentual das respostas para a análise dos dados do questionário, no que se refere aos: (1) aspectos sociais e (2) aspectos escolares e de trabalho. Desse modo, para a sistematização dos dados, cada questionário foi numerado sequencialmente (de 01 a 52), sendo realizada a tabulação organizada de números de respostas de acordo com as variáveis utilizando o apoio do programa Microsoft Excel 2019.

Já em relação ao terceiro aspecto investigado no questionário: (3) percepção sobre o impacto do ingresso na Educação do Campo na vida das estudantes, a sistematização e análise dos dados dos questionários ocorreram com base na análise de conteúdo (BARDIN, 1995). Para constituição das categorias de análise, realizamos diversas vezes a leitura das respostas constantes do questionário (MORAES, 1999). A definição das categorias deu-se a partir do conteúdo manifesto de cada estudante. Esses discursos foram organizados em tabela com auxílio do programa Microsoft Excel 2019. Foram estabelecidas as seguintes categorias de análise no aspecto relativo à percepção sobre o impacto do ingresso na Educação do Campo na vida das estudantes: formação profissional, gerenciamento familiar e papel social.

$\mathrm{Na}$ primeira categoria, agrupamos as respostas que se referiam aos impactos profissionais percebidos após o ingresso no curso. Na segunda categoria, enquadramos as respostas relacionadas à vida familiar dessas mulheres em seus assentamentos. E, por fim, na terceira categoria reunimos respostas que abordavam a percepção dessas mulheres em relação às mudanças em seus papéis na sociedade. 
Após o estabelecimento das categorias, buscou-se identificar discursos relacionados a cada categoria, atribuindo a cada um deles o valor 01 (um). Ao final, somou-se o número de valores obtidos em cada categoria e, posteriormente, com os valores totais em cada categoria, a partir dos quais foi construída uma tabela.

Para a análise das entrevistas, além da análise de conteúdo descrita anteriormente, utilizamos a história oral temática, que tem cruzado várias áreas do conhecimento e recorrido a diversos enquadramentos conceituais e metodológicos, como apontou Meihy (1996). Assim, buscamos nesse campo metodológico, as narrativas das mulheres que refletiram acerca de aspectos de suas vidas antes, durante e após o ingresso no curso da LEDUC. Recortes das narrativas estão disponibilizadas no texto no que tange aos três principais aspectos abordados durante a pesquisa: sociais, escolares e de trabalho e percepções em relação ao impacto do ingresso na Educação do Campo na vida das estudantes.

\section{Dados e reflexões}

\section{Aspectos sociais}

A maioria das mulheres (44\%) representadas nesta pesquisa é jovem, entre 18 a 23 anos de idade. Já as mulheres com mais de 38 anos também alcançaram uma proporção considerável (22\%). A faixa etária com menor representação foi a de 28 a 33 anos (7,2\%), seguida pelas faixas etárias de 33 a 38 anos (11,6\%) e 23 a 28 anos (14,3\%).

Esses dados instigam algumas reflexões acerca da juventude do campo que pode estar encontrando no ingresso no curso uma alternativa para a permanência no campo. Os números reiteram a afirmação de Stropasolas (2007), segundo a qual a juventude camponesa procura uma saída para permanecer no campo.

Notavelmente, Valadares e colaboradores (2016), investigando a respeito dos significados da permanência de jovens no campo, encontraram considerável aumento das taxas de permanência das mulheres no campo apontando para a possibilidade de reversão ou, pelo menos, atenuação da tendência de masculinização do campo. Tradicionalmente, as pesquisas sobre agricultura familiar e juventude camponesa destacam que a saída das mulheres das áreas rurais é proporcionalmente maior que o êxodo dos homens. A divisão sexual do trabalho no interior da unidade produtiva é apontada como sendo um dos principais fatores que fazem com que mulheres jovens busquem projetos de vida fora das áreas rurais (STROPASOLAS, 2007).

Essas relações de hierarquia reproduzem-se também no processo de sucessão, no qual os homens assumem, na maioria das vezes, a direção da unidade produtiva familiar, o que confirma e consolida ainda mais as desigualdades de gênero. Nesse contexto, conscientes desse processo e das baixas chances de serem ouvidas ou mesmo de protagonizarem o processo de sucessão, as mulheres buscam no estudo uma formação que permita o seu ingresso no mercado de trabalho urbano e a conquista de alguma forma de autonomia. Em muitos casos, essas jovens são incentivadas por suas famílias a estudar e a exercerem uma atividade urbana (CASTRO, 2010). No entanto, um curso diferenciado, específico para populações do campo, como são as licenciaturas do campo, pode contribuir para que as 
mulheres não sejam incentivadas a abandonarem a vida no campo e partir para o mercado de trabalho nas cidades.

Quanto ao estado civil das estudantes, o número de mulheres solteiras $(51,8 \%)$ é superior ao das casadas ou em união estável (39,3\%). Isso pode estar relacionado com a pouca idade das estudantes. Já as divorciadas correspondem a 7,2\% das participantes. Em relação à maternidade, o maior grupo de mulheres foi representado por aquelas que não têm filhas/filhos (48,6\%). Das que têm filhas/filhos, a maioria tem duas/dois (22,9\%), seguido pelas que têm apenas um/uma filha/filho (19,6\%). As mulheres com três $(7,2 \%)$ ou quatro filhas/filhos (1,7\%) são a minoria.

De fato, as mulheres do campo vivem em uma sociedade que é formadora por seres sociais, sendo marcada pelas relações de poder desiguais e patriarcais (CINELLI; JAHN, 2011), de modo que estudar requer uma organização familiar em que o marido e os filhos possam se adequar aos momentos em que a mãe está ausente de casa. Diante disso, uma acadêmica expõe que o fato de ser mulher, mãe e dona de casa é desafiante:

Eu acho que o papel é esse: de mostrar que a mulher tem que ser protagonista da história dela, de estudar, porque é um desafio muito grande para a mulher estudar, ainda mais no nosso caso, onde maioria das mulheres do nosso curso é do assentamento, então o desafio é ainda maior né. (Estudante I).

As mulheres casadas e as que têm filhos precisam lidar com a vida de mãe, dona de casa, trabalhadora do campo, além de, muitas vezes, ter de trabalhar fora de casa. Essas múltiplas funções ficam evidentes nos relatos dos maiores desafios para estar e permanecer no curso. A violência de gênero revela-se por meio de episódios de violências psicológicas, morais, patrimoniais e físicas, estabelecendo relações de dominação e subjugação física e subjetiva contra as mulheres do campo (TARDIN, 2012). Nesse sentido, para a grande maioria das mulheres do curso, a mulher do campo é sinônimo de superação da opressão e preconceitos, assim como no caso da estudante C, que não teve o apoio do esposo e para continuar seus estudos decidiu se separar, como expressa:

A mulher do campo foi à luta, ultrapassou as perspectivas assim e foi estudar. Eu tive apoio para estudar do meu pai e da minha mãe, do meu marido não. Para eu estudar mesmo, a minha história foi meio triste, eu tive que separar. Depois de dois anos o meu marido voltou, aí eu falei para ele que estava estudando e não ia parar. (Estudante C).

Tal situação não é apenas realidade das mulheres camponesas desse curso. A pesquisa desenvolvida por Silva (2011), feita com mulheres estudantes do curso de Pedagogia da Terra e Agronomia em Sergipe, encontrou situação semelhante. A autora menciona que em relação às casadas e com filhos, alguns maridos não permitem que as esposas deem continuidade aos estudos, ou quando permitem, não ficam com as crianças para que elas possam ir à escola, fazendo com que abandonem os cursos. As mulheres ainda estão sujeitas às ordens do marido ou companheiro, reafırmando a força dos valores da família patriarcal no meio rural (SILVA, 2011). 
Tal situação é relevante, pois como observamos neste estudo, as mulheres casadas e com filhos são minoria, de forma que esses dados podem sugerir que esse grupo de mulheres pode estar tendo maior dificuldade em acessar a universidade por conta dos papéis de gênero que estão impostos para as mulheres camponesas.

É notável que o patriarcado no campo, assim como nas cidades e aldeias, é resultado desses processos que concebem relações de desigualdades sociais de forma hegemônica. Esse sistema impõe-se no campo da mesma forma perversa que assola a sociedade como um todo: na supremacia masculina, nas relações sociais e na representação em privados e públicos (FEDERICI, 2010).

0 brutal impacto disso é a divisão do trabalho com base no gênero, que acaba conferindo à mulher jornadas mais duras, responsabilizando-a pelos cuidados com a família, manutenção do ambiente doméstico (como atividades centrais da sua existência) e atuação na produção agrícola (TARDIN, 2012). A entrevista da estudante E revela esse aspecto:

Tenho que cuidar da casa, filhos, marido. Meu marido quer mais atenção que os filhos e trabalhar e dar conta disso tudo é puxado, mas eu acho que a gente é capaz, a gente se vira, nem que a gente se arrebenta toda. No fim a gente dá conta, mas eu acho que o papel da mulher no curso é esse de construir a história de cada uma. (Estudante E).

Sendo assim, garantir o acesso das mulheres à universidade pelo regime da alternância (tempo-comunidade e tempo universidade) tem sido uma das formas de colaborar para superar as imensas desigualdades entre gênero no campo, embora não implique resolver todos os problemas das mulheres. Essa população encontra diferentes desafios no decorrer do curso, devido aos papéis de gênero, como menciona a estudante A:

Eu tive muita dificuldade em deixar a família em casa. Quando comecei a estudar a mais nova tinha um ano, as primeiras etapas que deram certo de ser nas férias, todas elas iam para casa da minha mãe e aí elas ficavam 15 dias de férias lá. Lá é mais tranquilo, porque o meu marido também tem seus compromissos. Eu tiro o chapéu para qualquer mulher que está lá estudando com filho, porque o minuto que você tem para dar uma descansada e estudar um pouco, você tem que dar atenção aos filhos. (Estudante A).

Silva (2011) aponta que a distância dos filhos, a dupla jornada de trabalho, o longo período de alojamento no tempo-universidade, somados à presença de homens, à desconfiança do marido, à conciliação das tarefas domésticas com os estudos, à discriminação da sociedade, às cólicas menstruais são as principais dificuldades que permeiam o processo de formação acadêmica.

Nesse contexto, é importante observar que Faleiro e Farias (2017), ao pesquisar o perfil de mulheres camponesas do curso de Licenciatura em Educação do Campo de uma Universidade de Goiás (UFG), encontraram uma situação oposta à encontrada neste estudo. Na UFG, o perfil das mulheres estudantes é de casadas, com filhos e com idade 
entre 30 e 40 anos, o que evidencia as particularidades de cada curso em cada instituição de ensino superior no Brasil.

Quando olhamos para aspectos relativos à moradia, encontramos que a maioria das participantes (85\%) são mulheres camponesas provenientes de 16 assentamentos, de 13 municípios do estado, além de encontrarmos representantes que moram na cidade $(11,5 \%)$ e em aldeia indígena (3,5\%). Os municípios que abrigam a maioria das mulheres assentadas são Sidrolândia (27\%) e Ponta Porã (18\%), seguidos dos municípios de Itaquirai e Nova Alvorada do Sul (9\% cada), Nioaque (6\%), Corumbá, Itaporã, Rio Brilhante (4\% cada), Naviraí e Nova Andradina (2\% cada). Já as mulheres que moram na cidade estão nos municípios de Dourados (8,5\%) e Campo Grande (3\%); e as que moram na aldeia provêm do município de Amambai (3,5\%), da aldeia Amambai e pertencem à etnia Guarani e Kaiowá. Em relação à situação da moradia (se é própria, cedida, alugada, ou outra situação) constatamos que a maioria das mulheres mora em casas consideradas própria (58\%). Uma minoria $(12,5 \%)$ habita em casas alugadas, situação comum entre as mulheres que moram nas cidades.

No Estado de Mato Grosso do Sul (MS) foram conquistados 204 assentamentos, que hoje abrigam 27.764 famílias em uma área de 716.212,19 hectares (BRASIL, 2017). Assim, a agricultura familiar no Estado corresponde a 14\% do Valor Bruto da Produção Agropecuária - VBP, que é responsável por 46\% do pessoal ocupado no meio rural, o que corresponde a 97.431 pessoas (GUILHOTO et al., 2007). Assim, podemos notar que a LEDUC está tendo êxito em atingir mulheres advindas do campo, aumentando seu potencial para atuarem e permanecerem nos próprios contextos como sujeitas do campo, como destaca a estudante G:

A LEDUC nos oferece a oportunidade de cursar uma faculdade que permite a gente continuar no campo. Oportunidade de contextualizar conhecimento científico com conhecimento comum da população do campo. (Estudante G).

Além disso, os dados expressam uma diversidade de localidades nas quais as acadêmicas estão presentes e o quanto alguns municípios estão distantes do local onde a universidade está localizada, como é o caso de Corumbá/MS, localizada a $600 \mathrm{~km}$ de distância de Dourados/MS, município onde o curso é ofertado no tempouniversidade (presencial).

É importante pontuarmos que a organização curricular dessa graduação, em esfera nacional, prevê etapas presenciais (semelhantes a semestres de cursos regulares), ofertadas em regime de alternância entre tempo-universidade e tempo-comunidade, tendo em vista a articulação profunda entre educação e a realidade específica das populações do campo. Além disso, essa metodologia de oferta também evita que o ingresso de jovens e adultos na Educação Superior reforce a alternativa de deixar de viver no campo, bem como objetiva facilitar o acesso e a permanência no curso de educadoras/es que trabalham nas Escolas do Campo (MOLINA; SÁ, 2011).

Por outro lado, é relevante o fato de que entre os movimentos sociais que reivindicam acesso ou permanência na terra podem ser citadas diversas organizações protagonizadas ou formadas unicamente por mulheres, dessa forma, elas foram e são 
protagonistas na conquista da terra. Entretanto, diversas lutas que as mulheres travam no mundo são mais do que uma defesa ou apropriação de suas terras, mas uma forma de promover a agricultura de subsistência e a utilização não comercial dos recursos, contribuindo, assim, para a segurança alimentar de milhões de pessoas (FEDERICI, 2013). A partir desse ponto de vista, podemos refletir que as mulheres da LEDUC estão ampliando o projeto de construção de novas relações a partir da reconstrução de uma educação voltada para o modo de vida de suas comunidades, além de proporcionarem a permanência de mulheres no campo.

\section{Aspectos escolares e de trabalho}

$\mathrm{Na}$ análise das condições escolares anteriores ao ingresso no curso, verificamos que a grande maioria das mulheres é proveniente de escolas do campo/escolas rurais (73\%) em contraposição às que estudaram em escolas na cidade (27\%). A insatisfação encontrada nas escolas rurais fica evidente na seguinte exposição:

Eu estudei muito quando fiz o Ensino Médio. Fiz em uma escola na comunidade rural e lá a grade do Ensino Médio não tinha Química, Física e Biologia. Então para mim foi um desafio enorme quando entrei no curso, mas acordava todos os dias três da manhã antes de sair para trabalhar, estudava pelo menos duas horas todos os dias. Para mim foi puxado. (Estudante A).

De fato, a educação rural esteve quase sempre associada a uma situação de precariedade, de atraso, sendo caracterizada como de pouca qualidade, com recursos pedagógicos escassos e estrutura física inadequada. Assim, essa educação, em suas correntes mais conservadoras, ignora e despreza a realidade que se propõe a trabalhar, tendo origem no pensamento de hegemônico latifundiário, de controle político sobre a terra e sobre aqueles que nela trabalham e vivem. Essa educação é moldada por valores e princípios desvinculados da cultura e da familiaridade que os sujeitos campesinos têm sobre a água, o solo, a floresta, as culturas e manejos, a pesca, enfim, a ligação humana com a natureza e com os outros seres humanos (MOLINA; JESUS, 2004).

Bof e Conte (2019), analisando os dados sobre os índices de escolarização da população urbana e rural, verificaram que as desigualdades dos níveis de escolarização de pessoas do meio rural em relação ao meio urbano é explícita, de forma que as populações campesinas passaram no decorrer da história por um duplo processo de dicotomização: 1) a da negação de uma escola plena no campo para ser afirmada na cidade; 2) e da imposição de um currículo escolar urbano às poucas escolas do campo, negando-lhes a possibilidade de um currículo contextualizado e próprio.

Além disso, observamos que somente seis mulheres (11\%) têm outra graduação (duas em Serviço Social, duas em Pedagogia, uma em Matemática e uma em Ciências da Natureza). As demais mulheres (89\%) tiveram a LEDUC como a primeira e única oportunidade de ingresso no ensino superior. Esses dados confirmam que, historicamente, foi negado às classes populares, como o campesinato, o acesso às instituições educacionais para que assim pudessem permanecer dominadas e subjugadas pelas elites dominantes. 
De fato, no Brasil, quando pensamos no fracasso e na exclusão que assolam o sistema de ensino superior, precisamos fazer referência às classes populares. É impossível discutir a escolarização das classes populares sem nos pautarmos na longa história de fracassos diversos que, por inúmeros caminhos, têm negado aos estudantes a possibilidade de ter a experiência do êxito, em uma relação em que a escola ou a universidade se configure como um espaço significativo de ampliação de conhecimentos para todas e todos. No entanto, os processos compelidos no intuito de ampliar o acesso à educação e de garantir a permanência das e dos estudantes não expressam claramente o compromisso com a educação das classes populares (ESTEBAN, 2007).

No terreno profissional, as mulheres, em sua maioria (70\%), ainda não estão inseridas profissionalmente nas escolas do campo. É verdade também que a falta de professores oriundos do campo tem preocupado a população camponesa em diferentes regiões do país. 0 fato dos profissionais da educação não pertencerem à comunidade tem gerado alguns problemas para a educação dos seus filhos e filhas, pois muitos(as) professores(as) desconhecem a luta e passam a fazer críticas infundadas com relação ao assentamento e ao processo de conquista da terra (SILVA, 2011).

No entanto, com o processo de redemocratização do país e o fortalecimento dos Movimentos Sociais do Campo, tem ocorrido um movimento de exigência social e política da democratização do acesso à universidade como bem da sociedade, dando aos povos do campo a oportunidade de ingressar nas instituições de ensino superior (SANTOS, 2006). A LEDUC é fruto desse movimento de luta e tensionamento dos movimentos sociais contra o Estado, assim como aponta a estudante C:

Uma faculdade que segue os padrões regulares do mercado não insere a população do campo. Para gente conseguir mesmo fazer uma faculdade tem que ser específica para a gente, como a LEDUC é. Estamos a $370 \mathrm{~km}$ da cidade mais próxima e o Estado oferece poucas oportunidades para a população do campo. Eles limitam mesmo a nossa participação. Mas com muita luta estamos conquistando o nosso espaço. Já conseguimos um curso específico para a gente. (Estudante C).

Em contrapartida, quando investigamos como as mulheres do curso se veem em relação ao trabalho, relatamos que se identificam profissionalmente como sendo principalmente estudantes (35\%), agricultoras (28\%), donas de casa (11\%). As demais consideram-se autônomas (11\%), trabalham no serviço de saúde como agente comunitária (10\%) ou são artesãs (5\%).

Nesse ponto, atentamo-nos para o fato de que a jornada de trabalho da mulher do campo é subestimada pelo fato do seu trabalho agrícola ser considerado uma extensão do trabalho doméstico. Assim, as mais jovens preferem se identificar como estudantes ao invés de agricultoras, mesmo trabalhando na lida do lote todos os dias. De fato, as questões de gênero ficam evidentes nesse aspecto, já que a desvalorização do papel da mulher na agricultura demonstra a subordinação e a subvalorização desse trabalho, que a condiciona ao status de membro não remunerado da família e expressa uma desigualdade de gênero que mascara o significado da inserção produtiva das mulheres (SAFFIOTI, 2013).

Inúmeros estudos apontam que as atividades das mulheres camponesas não estão restritas ao cuidado reprodutivo, pois também realizam atividades nas lavouras de 
produção de alimentos que não são reconhecidas como parte produtiva da agricultura. Inclusive, em grande parte das vezes, essas mulheres sequer são consideradas agricultoras, sendo conhecidas como a filha ou a mulher de determinado agricultor (ALVES; SELL; CASTRO, 2018).

É fato a importância das mulheres na composição de grande parte da força de trabalho agrícola mundial, de forma que desempenham um papel vital para suas famílias e comunidades produzindo grande parte dos alimentos, já que são responsáveis pelas hortas, pelo manejo dos animais, pelo processamento, armazenamento e preparo dos alimentos, além dos cuidados com os idosos, com os enfermos e com as crianças (FEDERICI, 2013; KOROL, 2016). No entanto, essas mulheres enfrentam profundas dificuldades de acesso a recursos e direitos básicos para além da educação, como, por exemplo, terra, assistência técnica e crédito, que poderiam lhes garantir autonomia e reconhecimento (SHIVA, 2010).

Assim como encontrado neste trabalho, Negretto e Silva (2018) realizaram um trabalho com mulheres assentadas da Reforma Agrária objetivando problematizar as relações de gênero e poder ligadas à divisão sexual do trabalho entre homens e mulheres de assentamentos localizados no interior do Rio Grande do Sul. Verificaram que 90\% das mulheres camponesas pesquisadas declararam não se identificar como trabalhadoras, sobretudo, porque realizam tarefas secundárias em relação aos produtos economicamente mais importantes para a conformação da renda familiar. As autoras refletem que ainda que o trabalho cotidiano dessas mulheres inclua a elaboração de produtos que são vendidos nas feiras e geram receitas para a propriedade, raramente consideravam essas tarefas como trabalho remunerado.

Quando refletimos a respeito da inserção das estudantes, encontramos que 30\% estão inseridas nas escolas do campo trabalhando como professoras (65\%) ou como técnicas administrativas, inspetoras de alunos e merendeiras (35\%). As professoras das escolas do campo estão atuando principalmente nos anos finais do Ensino Fundamental e Ensino Médio. Esses dados são relevantes. Ao analisar o Projeto Pedagógico Curricular (UFGD, 2017) da LEDUC, temos que a primeira preferência para ingresso no curso é para os profissionais na área da Educação, no entanto, após 06 vestibulares (2019), o número de profissionais da Educação ainda é reduzido no estado do Mato Grosso do Sul.

Convém ressaltar ainda importantes números da realidade do campo que reforçam a situação de educadoras/es nas escolas do campo: o precaríssimo acesso das/os professoras/ es do meio rural à educação de nível superior. De acordo com dados da Pesquisa Nacional por Amostra de Domicílios - PNAD, de 2007, 61\% das/os educadoras/es que atuam no Ensino Fundamental e Médio nas escolas do campo não apresentam formação de nível superior, o que significa um contingente de aproximadamente 178 mil professores sem a formação adequada (MOLINA; SÁ, 2011).

\section{Impacto percebido na vida das estudantes após o ingresso na Educação do Campo}

Um fato bastante relevante é que todas as estudantes participantes da pesquisa $(n=52$, ou seja 100\%) afirmaram que o ingresso na LEDUC teve um impacto positivo em suas vidas. 
Quanto à percepção acerca do impacto do ingresso na Educação do Campo, foram consideradas as seguintes categorias de análises: formação profissional, gerenciamento familiar e papel social. A sistematização das percepções ocorreu ao atribuir-se um ponto cada vez que as falas das mulheres camponesas se relacionavam à categoria analisada. As percepções que não se encaixaram em nenhuma das categorias foram incluídas na categoria Outros. A tabela mostra a frequência de cada percepção sobre o impacto do ingresso na Educação do Campo na vida das estudantes citado pelas participantes da pesquisa (Tabela 1).

Tabela 1 - Frequência dos níveis de percepção de estudantes da Educação do Campo em relação ao impacto do ingresso no curso

\begin{tabular}{c|c}
\hline PERCEPÇÃO SOBRE O IMPACTO DO INGRESSO NA LEDUC & FREQUÊNCIA PERCENTUAL (\%) \\
\hline Formação Profissional & 35 \\
\hline Gerenciamento Familiar & 31 \\
\hline Papel Social & 30 \\
\hline Outros & 04 \\
\hline
\end{tabular}

Fonte: elaboração das autoras.

Verifica-se que o nível de percepção mais frequente se referiu à Formação Profissional (35\%), seguida pelas categorias: Gerenciamento Familiar (31\%) e Papel Social (30\%). No entanto, as três categorias tiverem percentuais bastante próximos, revelando que a percepção acerca do impacto do curso na formação cidadã dessas mulheres se distribuiu de forma homogênea entre as categorias estabelecidas.

Como afirma Arroyo (2007), a Educação do Campo é um direito a todos, no entanto, é necessário reconhecer as diferenças e as especificidade desse grupo de pessoas. Ofertar uma formação profissional que atenda os anseios das profissionais envolvidas é de extrema importância para a construção de uma educação básica plena e holística, que respeite toda a diversidade de povos e culturas. Assim, podemos afirmar que a LEDUC representa e é reconhecida pelas estudantes como uma conquista para as comunidades do campo, pois o regime de alternância possibilita o ingresso no ensino superior e, além disso, possibilita uma reflexão e busca por novas propostas para o campo, assim como para educação em geral, como afirma a estudante E:

A Educação do Campo é uma educação transformadora. Não é repetitiva e traz muita prática para as nossas crianças. A Educação do Campo faz uma junção da teoria com a prática, então é uma educação posta em prática. É realmente a melhor educação que eu vi até hoje. (Estudante E).

Arroyo (2007) menciona que para uma formação específica para a/o educador(a) do campo é necessário propiciar estudos e discussões em torno de problemas que envolvem as diferentes temáticas interligadas ao um projeto educativo para o campo. Nesse sentido, as mulheres acadêmicas da LEDUC foram unânimes em mencionar que ao ingressarem 
no curso passaram a olhar a terra e a vida no campo desde outra perspectiva e assim passaram a valorizar a vida no campo e os conhecimentos associados:

\begin{abstract}
Para mim é de grande valia os conhecimentos práticos que a gente tem no ensino nesse curso. Passamos a relacionar o conhecimento científico com o popular. Por exemplo: o estudo da Química que está na fermentação do queijo e podemos usar nas aulas práticas de química. Havia muito conhecimento que eu não sabia utilizar na educação, então eu acho que é muito importante esse ensino que se relaciona com a nossa vida. Os professores ensinam muita coisa prática, que está na nossa frente em casa e a gente não sabia como utilizar. (Estudante H).
\end{abstract}

Dessa forma, entendemos que os cursos específicos que atendem a formação dos profissionais das classes populares precisam conhecer e dialogar com a realidade e a dinâmica das comunidades onde estão inseridos os estudantes, colocando esses sujeitos como protagonistas na construção do conhecimento (FREIRE, 1983). Notamos que a LEDUC tem propiciado reflexões nesse sentido, já que as estudantes relatam o quanto essa formação diferenciada contribuiu para mudanças no sentido da percepção e da valorização dos saberes do campo:

Mudamos muito! 0 modo de agir, o modo de pensar. A parte que refletimos sobre o papel da escola. Muitas coisas que a gente não dava valor na vida no sítio agora percebemos o quanto é importante. (Estudante I).

Minha opinião mudou muito a partir do momento que eu comecei a entender o quanto a vida na roça é rica. A minha filha fala: você cresceu demais! (Estudante F).

Assim, podemos notar que o ingresso no curso proporcionou mudanças na vida das mulheres, de forma que o acesso ao ensino superior é um elemento importante para o reconhecimento da autonomia da mulher, da construção da sua emancipação e da sua comunidade, pois uma formação específica como a Educação do Campo faz com que essas mulheres se vejam como sujeitas essenciais na construção de uma educação voltada para a sua comunidade (SILVA, 2011).

Oliveira et al. (2018), por meio da análise de discursos e narrativas de quatro mulheres camponesas capixabas materializadas nos Cadernos da Realidade dos Estudantes da Licenciatura em Educação do Campo/UFES, encontraram indícios de permanências e descontinuidades nas trajetórias dessas mulheres durante o período investigado. Como permanências, destacaram a mulher ocupando os espaços domésticos, sobretudo, exercendo atividades desprovidas de valor econômico. Já os indícios de descontinuidades são apontados pelas autoras/es tais como: a inserção ainda criança no processo de escolarização, o protagonismo das mulheres no âmbito doméstico, comunitário e nos espaços mais amplos da sociedade, como a universidade.

Assim, nesta pesquisa, as mulheres apontam fortemente para mudanças em seus papéis domésticos e, consequentemente, sociais como resultado do ingresso do curso de Educação do Campo. Esse fato está em consonância com o Projeto Pedagógico Curricular do curso de Licenciatura em Educação do Campo da UFGD, que aponta a Educação do 
Campo tendo como fio condutor a educação como um compromisso político diante da complexidade da sociedade.

Assim, de acordo com esse documento, o curso tem como meta "a construção de uma prática educativa pautada no respeito às diferenças e aos direitos humanos e sociais, essências para a construção de uma equidade nas relações culturais e de gênero no campo", para que assim seja possível "criar nas escolas, outras referências para a construção de conhecimentos que libertam e não que dominam e controlam (UFGD, 2017, p. 12). Cabe ressaltar que até o presente ano, dos 42 cursos de graduação da UFGD, o curso de Licenciatura em Educação do Campo é o único que oferta uma disciplina obrigatória que discute especificamente relações de gênero (disciplina Relações de Gênero e Poder).

\section{Considerações finais}

Este trabalho buscou analisar o perfil social das mulheres estudantes da Educação do Campo, além de refletir a respeito de aspectos escolares e profissionais dessas mulheres e ainda identificar a percepção dessas estudantes em relação ao impacto em suas vidas após o ingresso no curso.

0 perfil das mulheres é de idade inferior a 28 anos, moradoras do campo, solteiras e sem filhos. Em relação aos aspectos escolares, cursaram o ensino médio em escolas do campo e encontraram na LEDUC a possibilidade de ingresso no ensino superior devido a vários fatores, dentre eles, o método da Pedagogia da Alternância, em que alterna o processo de ensino-aprendizagem entre os períodos tempo-universidade e tempo-comunidade, possibilitando, assim, que estudem de acordo com suas condições objetivas. Em relação aos aspectos laborais, não estão inseridas profissionalmente nas escolas do campo, identificam-se como estudantes e enfrentaram desafios relacionados a questões de gênero.

Quando nos debruçamos sobre a percepção de estudantes da Educação do Campo em relação ao impacto do ingresso no curso, observamos que todas as participantes acreditam que o curso propiciou uma mudança positiva em suas vidas. Assim, de acordo com a percepção das camponesas, as três categorias estabelecidas tiverem um nível de relevância sintonizado, revelando que a percepção sobre o impacto do curso na vida dessas mulheres se distribuiu de forma homogênea entre as categorias, ou seja, essas mulheres percebem de maneira semelhante o impacto que o ingresso no curso gerou em suas vidas profissionais, domésticas e sociais.

Dessa forma, entendemos que a LEDUC tem tido êxito na transformação das desigualdades de gênero e no empoderamento das mulheres contribuindo para uma nova organização social, de forma que as discrepâncias de classe e gênero possam ser superadas. Ressaltamos a importância dessas licenciaturas, a partir da capacidade de atuar do ponto de vista de uma consciência de classe favorável à classe trabalhadora do campo, por meio do rompimento com as relações capitalistas e patriarcais.

Concluímos que o processo de ingresso e o decorrer da trajetória no curso da LEDUC impacta na vida das mulheres estudantes fazendo com que se reconheçam como sujeitas autônomas e protagonistas na construção da Educação do Campo, tanto na universidade quanto em suas comunidades. Os processos de reflexões, construções e desconstruções 
nesse caminhar são ferramentas importantes e com capacidade de transformar as relações patriarcais do campo.

Da mesma forma, notamos que a valorização cultural e profissional é capaz de romper relações de dominação, inferiorização e subordinação dessas mulheres, tanto na esfera pública quanto na privada. Assim, ao reconhecer e valorizar a cultura do campo, ao mesmo tempo em que se rompe com aspectos negativos de opressão, é possível alterar os caminhos culturais dessas comunidades para que lutas e sonhos possam ser construídos.

Enfım, cabe ressaltar que esta pesquisa é fruto também das vivências das próprias estudantes e seus processos de conflitos, desconstrução e aprendizados em todo o processo dentro da universidade. Ao entrar na Licenciatura em Educação do Campo, por meio disciplina Relações de gênero e poder logo nos primeiros semestres, o tema adentra a sala de aula, expande-se para a vida e esparrama-se pelos campos do estado de Mato Grosso do Sul.

Diante do exposto, é necessário esmiuçar as relações de gênero de camponesas na busca pela construção de uma Educação do Campo que fortaleça o protagonismo das mulheres, visando a seu empoderamento e a promoção da equidade e inclusão social desse grupo historicamente excluído da construção de políticas públicas educacionais.

\section{Referências}

ALVES, Giovana Sitó; SELL, Léia Beatriz; CASTRO, Amanda Motta. 0 trabalho da mulher no campo e suas invisibilidades. Revista Sures, Foz do Iguaçu, n. 11, p. 1-10, 2018.

ARROYO. Miguel Gonzáles. Ações coletivas e conhecimento: outras pedagogias? In: UNIVERSIDADE Popular dos Movimentos Sociais, 2009. Disponível em: http://www.universidadepopular.org/site/media/ leituras_upms/Acoes_Coletivas_e_Conhecimento_30-11-09.PDF. Acesso em: 17 fev. 2021.

ARROYO. Miguel Gonzáles. Educação do campo. In: CALDART, Roseli et al. (org.). Dicionário da educação do campo. Rio de Janeiro: Escola Politécnica de Saúde Joaquim Venâncio: Expressão Popular, 2012. p. 257-265.

ARROYO, Miguel Gonzáles. Políticas de formação de educadores(as) do Campo. Cadernos Cedes, Campinas, v. 27, n. 72, p. 157-176, 2007.

BARDIN, Laurence. Análise de conteúdo. Lisboa: Edições 70, 1995.

BOF, Leonir Amantino; CONTE, Isaura Isabel. Camponeses e a educação do campo no Brasil. Revista da Faculdade de Educação, Cáceres, v. 27, n. 1, p. 143-162, 2019.

BRASIL. Ministério da Agricultura. Instituto Nacional de Colonização e Reforma Agrária. Superintendência Regional de Mato Grosso do Sul. Painel de assentamento no Estado de Mato Grosso do Sul. Campo Grande: Incra, 2017. Disponível em: http://painel.incra.gov.br/sistemas/index.php. Acesso em: 04 mar. 2019.

CALDART, Roseli Salete. Educação do campo. In: CALDART, Roseli Salete et al. (org.). Dicionário da educação do campo. Rio de Janeiro; São Paulo: Escola Politécnica de Saúde Joaquim Venâncio: Expressão Popular, 2012. p. 257-265. 
CALDART, Roseli Salete. Sobre educação do campo. In: SANTOS, Clarice Aparecida dos (org.). Educação do campo: campo, políticas públicas, educação. Brasília, DF: Incra: MDA, 2008. p. 67-97.

CASTRO, Elisa Guaraná. Juventude rural: -mais do que uma palavra- uma problematização da construção de categorias sociais. In: MOREIRA, Roberto José; BRUNO, Regina Landin (org.). Interpretações, estudos sociais e política. Rio de Janeiro: Mauad X; Seropédica: Edur, 2010. p. 61-94.

CINELLI, Catiane; JAHN, Elisiane Fatima. A constituição de identidades camponesa e feminista no Movimento de Mulheres Camponesas. Revista Espaço Acadêmico, Maringá, v. 10, n. 117, p. 86-92, 2011.

CRESWELL, John W. Projeto de pesquisa: métodos qualitativo, quantitativo e misto. Tradução Magda Lopes. 3. ed. Porto Alegre: Artmed, 2010.

CRESWELL, John W.; CLARK, Vicki. Choosing a mixed methods design. Designing and Conducting mixed Methods Research, New York, v. 2, p. 53-106, 2011.

ESTEBAN, Maria Teresa. Educação popular: desafio à democratização da escola pública. Cadernos Cedes, Campinas, v. 27, n. 71, p. 9-17, 2007.

FALEIRO, Wender; FARIAS, Magno Nunes. Inclusão de mulheres camponesas na universidade: entre sonhos, desafios e lutas. Educação e Pesquisa, São Paulo, v. 43, n. 3, p. 833-846, 2017.

FEDERICCI, Silvia. Calibã e a bruxa: mulheres corpo e acumulação primitiva. São Paulo: Elefante, 2017.

FEDERICI, Silvia. Mujeres, luchas por la tierra y globalización: una perspectiva internacional. In: FEDERICI, Silvia. Revolución en punto cero: trabajo doméstico, reproducción y luchas feministas. Madrid: Traficantes de Sueños, 2013. p. 15-27.

FREIRE, Paulo. Pedagogia do oprimido. Rio de Janeiro: Paz e Terra, 1983.

GUILHOTO, Joaquim José Martins et al. PIB da agricultura familiar: Brasil - Estados. Brasília, DF: MDA, 2007.

KOROL, Claudia. Somos tierra, semilla, rebeldía: mujeres, tierra y territorio en América Latina. Barcelona: Grain: Acción por la Biodiversidad y América Libre, 2016.

LÜDKE, Menga; ANDRE, Marli. A pesquisa em educação: abordagens qualitativas. Rio de Janeiro: E.P.U, 2013.

MEIHY. José Carlos S. Bom. Manual da história oral. São Paulo: Loyola, 1996.

MOLINA, Mônica Castagna. Expansão das licenciaturas em educação do campo: desafios e potencialidades. Educar em Revista, Curitiba, n. 55, p. 145-166, 2015.

MOLINA, Mônica Castagna; FREITAS, Helana Célia de Abreu. Educação do campo. Em Aberto, Brasília, DF, v. 24, n. 85, p. 1-177, 2011. 
MOLINA, Mônica Castagna; JESUS, Sônia Meire Azevedo de. Contribuições para a construção de um projeto de educação do campo. Brasília, DF: Articulação Nacional por uma Educação do Campo, 2004.

MOLINA, Mônica Castagna; SÁ, Laís Maria Borges de Mourão. Licenciatura em educação do campo da Universidade de Brasília: estratégias político pedagógicas na formação de educadores do campo. In: UFMG. UnB. UFS. UFBA. (org.). Licenciaturas em educação do campo: registros e reflexões a partir das experiências piloto. Belo Horizonte: Autêntica, 2011. p. 35-64.

MORAES, Roque. Análise de conteúdo. Revista Educação, Porto Alegre, v. 37, p. 7-32, 1999.

NEGRETTO, Carla; SILVA, Márcia Alves. Problematizando o trabalho invisível das mulheres e a divisão sexual de trabalho no campo: uma parceria entre educação popular e feminismo. Revista Brasileira de Educação do Campo, Tocantesinópolis, v. 3, n. 4, p. 1184-1201, 2018.

OLIVEIRA, Deiviani et al. Trajetórias de mulheres camponesas no Espírito Santo: permanências e descontinuidades. Revista Brasileira de Educação do Campo, Tocantesinópolis, v. 3, n. 4, p. 12211248, 2018.

PEREIRA, Maria de Lourdes Soares. As contribuições da licenciatura em educação do campo na transformação das relações de gênero. Revista Com Censo, Brasília, DF, v. 4, n. 7, 2016.

RIBEIRO, Elisa Antonia. A perspectiva da entrevista na investigação qualitativa. Revista Evidência, Olhares e Pesquisas em Saberes Educacionais, Araxá, v. 4, n. 4, p. 129-148, 2008.

SAFFIOTI, Heleieth. A mulher na sociedade de classes: mito e realidade. 3. ed. São Paulo: Expressão Popular, 2013.

SHIVA, Vandana. Abrazar la vida: mujer, ecologia y desarrollo. Madrid: Horas y Horas, 2010. 320p.

SILVA, Denice Batista. A mulher camponesa no ensino superior: o caso de Sergipe. In: SANTOS, Clarice Aparecida dos; MOLINA, Monica Castagna; JESUS, Sonia Meire dos Santos Azevedo de (org.). Memória e história do Pronera: contribuições para a educação do campo no Brasil. Brasília, DF: Ministério do Desenvolvimento Agrário, 2010. p. 139-156.

STROPASOLAS, Valmir Luiz. Um marco reflexivo para a inserção social da juventude rural. In: CARNEIRO, Maria José; CASTRO, Elisa Guaraná (org.). Juventude rural em perspectiva. Rio de Janeiro: Mauad X, 2007. p. 279-296.

TARDIN, José Maria. Cultura camponesa. In: CALDART, Roseli et al. (org.). Dicionário da educação do campo. Rio de Janeiro: Escola Politécnica de Saúde Joaquim Venâncio: Expressão Popular, 2012. p. 178-186.

UFGD. Universidade Federal da Grande Dourados. PPC - Projeto Pedagógico Curricular do curso de licenciatura em educação do campo da universidade federal da Grande Dourados. Dourados: UFGD, 2017. 
VALADARES, Alexandre Arbex et al. Os significados da permanência no campo: vozes da juventude rural organizada. In: SILVA, Enid Rocha Andrade da; BOTELHO, Rosana Ulhôa (coord.). Dimensões da experiência juvenil brasileira e novos desafios às políticas públicas. Brasília, DF: IPEA, 2016. p. 59-94.

Recebido em: 07.04.2019

Revisado em: 11.10.2019

Aprovado em: 03.03.2020

Laura Jane Gisloti é doutora em biologia animal pela Universidade Estadual de Campinas (Unicamp). É professora da Universidade Federal da Grande Dourados (UFGD) onde atua na linha de pesquisa território e sustentabilidade (PPGET/UFGD).

Dalva Melo dos Santos é licenciada em educação do campo com habilitação em ciências da natureza pela Universidade Federal da Grande Dourados.

Cíntia Melo dos Santos é doutora em educação matemática pela Universidade Federal de Mato Grosso do Sul (UFMS). É professora da Universidade Federal da Grande Dourados, onde atua no grupo de pesquisa em Didática da Matemática (DDMat).

Sandra Procópio da Silva é mestre em sociologia pela Universidade Federal da Grande Dourados. É Doutoranda no Programa de Pós-Graduação em Geografia (PPGG/UFGD) e professora da Faculdade Intercultural Indígena (FAIND/UFGD). 